\title{
Worker Assignment in Dual Resource Constrained Assembly Job Shops with Worker Heterogeneity: An Assessment by Simulation
}

Matthias Thürer (corresponding author), Haiwen Zhang, Mark Stevenson, Federica Costa and Lin Ma

\author{
Name: $\quad$ Prof. Matthias Thürer \\ Institution: Jinan University \\ Address: $\quad$ School of Intelligent Systems Science and Engineering \\ Jinan University (Zhuhai Campus) \\ 519070, Zhuhai, PR China \\ E-mail: matthiasthurer@workloadcontrol.com \\ Name: $\quad$ Haiwen Zhang \\ Institution: Jinan University \\ Address: $\quad$ School of Management \\ Jinan University \\ 510632, Guangzhou, PR China \\ E-mail: $\quad$ haiwzhang@gmail.com \\ Name: $\quad$ Prof. Mark Stevenson \\ Institution: Lancaster University \\ Address: Department of Management Science \\ Lancaster University Management School \\ Lancaster University \\ LA1 4YX - U.K. \\ E-mail: $\quad$ m.stevenson@lancaster.ac.uk \\ Name: $\quad$ Federica Costa \\ Institution: Politecnico di Milano \\ Address: $\quad$ Department of Management, Economics and Industrial Engineering \\ Via Lambruschini $4 / b$, \\ 20156, Milano, Italy \\ E-mail: $\quad$ federica.costa@polimi.it \\ Name: $\quad$ Lin Ma \\ Institution: Jinan University \\ Address: $\quad$ School of Management \\ Jinan University \\ 510632, Guangzhou, PR China \\ E-mail: $\quad$ malin15102939217@163.com
}

Keywords: Worker Assignment; Assembly Systems; Job Shop; Simulation; Dual Resource Constrained Shop. 


\title{
Worker Assignment in Dual Resource Constrained Assembly Job Shops with Worker Heterogeneity: An Assessment by Simulation
}

\begin{abstract}
Most shops in practice are constrained by more than one resource. Consequently, a large body of literature on dual resource constrained shops has emerged. This research typically focuses on worker assignment rules, with attention being on when and where to move workers. In contrast, the decision concerning who to reallocate to a station has received limited attention. The limited prior work assumes workers are assigned to a new station as soon as they become available or seeks to minimize the risk of worker idleness. Using simulation, we question this assumption and show that it can be beneficial to introduce additional worker idleness to ensure workers only work at their most efficient station(s). In general, it is less likely that there are several workers available for one station than it is for there to be multiple stations available for one worker. Consequently, the Who Rule is used less frequently than the Where rule and has less of an impact on performance. Finally, considering the criticality of work orders as part of the Where Rule is important in assembly shops; but if labor is heterogeneous then the focus should be on efficiency. The findings have important implications for research and practice.
\end{abstract}

Keywords: Worker Assignment; Assembly Systems; Job Shop; Simulation; Dual Resource Constrained Shop. 


\section{Introduction}

This study was motivated by an assembly job shop with dual resource constraints and a heterogeneous labor force observed in practice. An "assembly job shop" is hereby used to refer to a simple assembly system, where the final product (or assembly order) is made up of several subassemblies (or work orders) with independent routings that have to be coordinated in order for the subassemblies to arrive together at the final assembly station (e.g. Sculli, 1980; Adam et al., 1987; Philipoom et al., 1991; Lu et al., 2011; Thürer et al., 2012; Komaki et al., 2019; Shi et al., 2019). Meanwhile, being "dual resource constrained" (DRC) means that the shop is restricted by not one but two resources, most typically by machines and labor (e.g. Bobrowski \& Park, 1989; Felan et al., 1993; Malhotra et al., 1993; Fredendall et al., 1996; Bokhorst et al., 2004a; Bokhorst \& Gaalman, 2009; Thürer et al., 2019). Finally, "heterogeneous labor" refers to shops where workers are not perfectly interchangeable, i.e. they have different levels of proficiency at each station leading to potential productivity losses when workers are reassigned (e.g. Hogg et al., 1977; Bobrowski \& Park 1993; Bokhorst et al. 2004a; Lian et al. 2018). Taken together, these three elements create a complex planning and control problem that has received insufficient attention in the literature to date.

Given its practical importance, a large body of research has emerged on the problems of DRC shops. This work typically focuses on worker assignment rules, i.e. on decisions concerning when to move workers, where workers should be moved to, and who to move (e.g. Bobrowski \& Park, 1993; Malhotra \& Kher, 1994; Fredendall \& Melnyk, 1996; Jensen 2000; Kher, 2000; Bokhorst et al., 2004a; Salum \& Araz, 2009; Sammarco et al., 2014). However, while the decisions concerning when and where to move workers have received much research attention, the decision concerning who to reallocate to a station has received only limited attention. One explanation is that the latter decision only occurs in shops with a heterogeneous labor force. Moreover, the extant literature that considers the Who Rule assumes workers are assigned to a station as soon as they become available or seeks to minimize the risk of worker idleness (Bokhorst et al., 2004a). In contrast, it is argued here that if workers are heterogeneous and realize different service rates at different stations it can be more advisable to let the worker wait, and thus be idle, until a station at which he/she is more efficient needs a worker.

Meanwhile, an assembly system may introduce different priorities for the Where Rule. Previous literature on DRC shops has argued that the Where Rule should be based on urgency or on the workload requirements of the orders in a queue (for systems with homogenous labor), or efficiency (for systems with heterogeneous labor). Yet this literature typically neglects assembly systems. Assembly order performance in an assembly job shop is complex and 
depends on the progress of all work orders - final assembly cannot take place until all work orders have been finished and the work orders have arrived at the final assembly station. The coordination of work order progress on the shop floor is consequently a major focus of dispatching rules presented in the literature on assembly job shops (e.g. Sculli, 1980; Adam et al., 1987; Philipoom et al., 1991). These coordination rules seek to synchronize the material flow. Meanwhile, worker assignment rules determine the availability of resources or capacity - they consequently have a direct impact on work order progress. It is therefore argued here that the Where Rule should support co-ordination, for example, by assigning labor to a station with a "critical work order", referring to the last work order that is needed to complete an assembly order.

In response to the above, we use a simulation model of a DRC assembly job shop to assess the performance impact of different worker assignment rules that consider a delay to the worker assignment decision and critical parts under different degrees of worker heterogeneity. The intention is to contribute not only to the DRC literature, but also to assist practitioners in making worker assignment decisions.

The remainder of this paper is structured as follows. In Section 2, we review relevant literature and outline the two research questions that motivate our study. The simulation model used to evaluate performance is then described in Section 3 before the results are presented, discussed, and analyzed in Section 4. Finally, conclusions are presented in Section 5.

\section{Literature Review}

In general, a broad literature exists on a heterogeneous labor force in the context of DRC shops. This literature models worker heterogeneity either in the form of a flexibility matrix, which indicates whether a worker can work at a station, or in the form of an efficiency matrix, which reflects the proficiency of each worker at each station. These two perspectives are introduced in Section 2.1 and Section 2.2, respectively. Section 2.3 then discusses the main focus of our study - worker assignment rules - and introduces the two research questions that motivate our study.

\subsection{Worker Flexibility}

Labor flexibility has been defined as the number of different departments or stations at which a worker can perform operations (Fry et al., 1995). Nelson (1967) was one of the first to introduce the concept of labor flexibility, considering two polar extremes, i.e. a completely inflexible scenario, where each worker can only work at one station, and a completely flexible 
scenario where each worker can work at every station. These scenarios were extended by a further two scenarios to include where a worker can work at two or three stations in a five station DRC job shop by Park \& Bobrowski (1989). Park (1991) later added the scenario where a worker can work at four stations. Both studies concluded that cross-training workers, so they can work at multiple stations, leads to improved performance. A major insight however from these earlier studies was that most of the benefits associated with worker flexibility can be realized at moderate flexibility levels. Felan \& Fry (2001) later suggested that it is better to have a mix of workers with some having no flexibility and others being very highly flexible rather than all workers having equal flexibility. This finding was extended by Yue et al. (2008) who showed that a minimum level of flexibility is desired and that having long chains of workers with overlapping capabilities is better than having several short chains.

The idea of chaining originally emerged in the context of process flexibility (Jordan \& Graves, 1995), which can be defined as the ability of plants to produce different types of products (Bokhorst et al., 2004b). Linking products and plants by a single path allows for the shifting of product assignments across plants, thereby balancing the workload. This concept of chaining has received much attention in environments constrained by a single resource (Bokhorst et al., 2009), where the chains link products to plants (process flexibility), products to machines (routing flexibility), or workers to tasks (cross-training). Chaining in the context of worker flexibility however links workers to stations. Unlike with product assignments, this has no direct effect on the workload assigned to a station (which is reflected in the routing of an order). Rather, it enables worker assignment rules to balance the workload across workers (Bokhorst et al. 2004b), which is arguably more important in the context of DRC shops where labor is the main constraint. Linking workers to stations also allows for capacity adjustments if more than one worker can work at a station, such as if there are several identical machines at each station (see, e.g. Yue et al., 2008).

\subsection{Worker Efficiency}

Labor efficiency is here defined as the level of the service rate at which a worker can work at a station. The concept of flexibility discussed in Section 2.1 above does not consider this effect; rather, workers are assumed to either have the maximum level of efficiency or to be unable to work at a station. This would be an 'ideal' situation where operators are perfectly interchangeable without productivity losses due to different levels of proficiency. One of the first studies to question this assumption was presented by Bobrowski \& Park (1993), who used three efficiency matrices. Simulation results in Bobrowski \& Park (1993) showed that 
efficiency is likely to dominate worker assignment rules in contexts characterized by differing labor efficiencies. This study was later extended by Malhotra \& Kher (1994) who showed that it is better to train workers so that some machines always work faster, such as the first machine, or having some workers completely interchangeable and others less efficient. The latter is similar to the senior/junior worker concept proposed by Bobrowski \& Park (1993) and overlaps with the results in Felan \& Fry (2001) on labor flexibility, as discussed in Section 2.1 above. Brusco \& Johns (1998) later tested different cross-training configurations showing that crosstraining employees at $50 \%$ in secondary skill classes realizes the majority of the cost savings or performance benefits available from cross-training at full efficiency. Finally, the results in Bokhorst et al. (2004a) confirmed that a heterogeneous labor force (in terms of efficiency) leads to better performance compared to a homogeneous labor force if an appropriate worker assignment rule is in place.

\subsection{Worker Assignment}

This section only discusses the literature on DRC shops that is of relevance to our study; for an all-encompassing review, the reader is referred to Treleven (1989), Hottenstein \& Bowman (1998), and Xu et al. (2011). First, we only focus on literature in stochastic environments. This excludes most of the literature on advanced scheduling techniques (e.g. El Maraghy et al., 2000; Araz \& Salum, 2010; Jaber \& Neumann, 2010; Lei \& Guo, 2014; Lei \& Guo, 2015; Li et al., 2016; Zheng \& Wang, 2016; Zhang et al., 2017), which presupposes that demand and capacity availability are known in advance and therefore deterministic. In contrast, we consider a high variety make-to-order environment where processing times, routings, and the inter-arrival times of orders follow a stochastic process. It is this type of environment where worker assignment rules play a major role since worker assignment cannot be predetermined or scheduled. Second, we assume worker heterogeneity to be stable over time. Dynamic worker heterogeneity would interfere with the performance of worker assignment rules and potentially blur performance differences across rules. This excludes most of the literature on learning and forgetting (e.g. Malhotra et al., 1993; Fry et al., 1995; Kher et al. 1999; Kannan \& Jensen, 2004; Zamiska et al., 2007; Yue et al., 2008).

Literature on worker assignment rules typically focuses on decisions concerning when to move workers, where workers should be moved to, and who to move (e.g. Bobrowski \& Park, 1993; Malhotra \& Kher, 1994; Fredendall \& Melnyk, 1996; Jensen 2000; Kher, 2000; Bokhorst et al., 2004a; Salum \& Araz, 2009; Sammarco et al., 2014). There are mainly two types of When Rules applied in the literature: a 'centralized' rule that transfers a worker each time a job 
is completed and a 'decentralized' rule that transfers a worker after completing all jobs at the current station. The centralized rule tends to outperform the decentralized When Rule but at the expense of an increase in the number of worker transfers (Thürer et al., 2019). Meanwhile, it has been shown that incorporating future workload information into the When Rule does not improve performance enough to impact a manager's decisions (Fredendall et al. 1996). There also exists a broad set of different Where rules; however, the literature typically argues that the Where Rule has less impact than the When Rule (Xu et al. 2011). In general, while the decision concerning when to move workers and where workers should be moved to has to be made in every DRC shop, the question concerning who to move only has to be answered if there is worker heterogeneity. This may explain why the Who Rule has received less research attention.

A major study on the Who Rule was presented by Bokhorst et al. (2004a). The authors considered four different Who rules: (i) choose the available worker with the longest idle time, from Rochette \& Sadowski (1976); (ii) choose from the available workers randomly; (iii) choose the available worker who can perform the fewest tasks; and, (iv) choose the available worker who is the most efficient, from Hogg et al. (1977). While the former two rules neglect worker heterogeneity, the latter two explicitly consider flexibility and efficiency, respectively. An important aspect of both of the latter two rules is that they seek to minimize worker idle time. In contrast, here we argue that depending on the degree of heterogeneity in the efficiency level of workers, it may be a better decision to only assign a worker to the stations where he/she is most efficient. This means that a worker is not assigned to a station even if he/she is available and consequently becomes idle, except if it is one of his/her most efficient stations. This leads to the following research question:

RQ1: Is it advisable to introduce additional worker idle time in DRC shops with worker heterogeneity to ensure workers only work at their most efficient station(s)?

A simulation model of a DRC assembly job shop will be used to answer this question. The assembly job shop was chosen as a shop type commonly found in practice. Research on DRC shops is typically set in contexts without assembly structures. The assembly structure itself suggests refinements to the Where Rule. A broad literature exists on dispatching in assembly job shops (e.g. Sculli, 1980; Adam et al., 1987; Philipoom et al., 1991). Most of the rules described in this body of work base the dispatching decision on the remaining work orders, such as the Number of Unfinished Parts (NUP) rule (e.g. Maxwell \& Mehra, 1968). Similarly, we argue that existing worker assignment rules from the DRC literature should be enhanced to incorporate the number of critical parts in DRC assembly job shops. In response, we also ask: 
RQ2: Should critical parts be considered when assigning workers in DRC assembly job shops?

\section{Simulation}

Simulation is a powerful tool for experimenting with different system designs (Mourtzis, 2019). A stylized standard model of a DRC assembly job shop is used in this study to avoid interactions that may otherwise interfere with our understanding of the main experimental factors. While any individual DRC shop in practice will differ in many aspects from our stylized environment, the model used in this study captures the job and shop characteristics of high variety make-to-order shops, i.e. high routing variability, high processing time variability, and high arrival time variability. The shop and job characteristics modeled in the simulations are first summarized in Section 3.1. How we model labor heterogeneity is then outlined in Section 3.2 before the different worker assignment rules are discussed in Section 3.3. The priority dispatching rules applied for controlling the progress of work orders on the shop floor are then described in Section 3.4. Finally, the experimental design is outlined and the measures used to evaluate performance are presented in Section 3.5.

\subsection{Overview of Modeled Shop and Job Characteristics}

A simulation model of an assembly job shop has been implemented in SIMIO $^{\odot}$. The model is a generalization of assembly shop structures commonly found in practice (e.g. Silva et al., 2006; Stevenson \& Silva, 2008; Stevenson et al., 2011). It extends the pure job shop model proposed by Melnyk \& Ragatz (1989). We model a balanced shop to avoid distracting our focus away to unbalanced shops and fixed bottlenecks. The job shop contains six stations. In practice, each station may represent, for example, different machines such as a mill or a lathe. Each station is a single and unique capacity resource. As in previous DRC research, we consider machine capacity to be constant and we instead focus on different levels of labor capacity. Worker availability constrains the capacity. Only if a worker is assigned to a station is capacity realized and orders can be processed. We use only one staffing level since the impact of different staffing levels has recently been assessed in Thürer et al. (2019). We focus on the lowest staffing level from previous studies, i.e. 3 workers or $50 \%$ (e.g. Felan et al., 1993). This staffing level was chosen to allow for an equal distribution of stations across workers, which is required to realize a balanced shop, as will be described in Section 3.2 below.

All stations have an equal probability of being visited and a particular station is required at most once in the routing of a work order (a sub-assembly). Work orders leaving the job shop 
go to an assembly station where they await other work orders that make up the final assembly order. As in Lu et al. (2011), the assembly time is negligible in order to avoid distracting the focus of the study away from assembly orders to bottlenecks. When all work orders have arrived, the assembly order is considered complete and the work orders leave the simulation together as an assembled product. The number of work orders per assembly order is uniformly distributed between two and six.

Operation processing times for a fully efficient worker follow a 2-Erlang distribution with a mean of 1 time unit. Set-up times are considered sequence independent and part of the operation processing time. The travel times of workers are considered to be negligible. The inter-arrival time of assembly orders follows an exponential distribution. The mean is set such that, theoretically, workers are occupied $90 \%$ of the time for the scenario where worker efficiency is neglected by the worker assignment rule. Due dates are set exogenously by adding a uniformly distributed random allowance factor to the assembly order entry time. This allowance factor is set between 65 and 100 time units based on preliminary simulation experiments. All work orders of an assembly order have the same due date. Finally, Table 1 summarizes our job and shop characteristics.

\section{[Take in Table 1]}

\subsection{Labor Heterogeneity}

Our main environmental variable is worker heterogeneity. Worker differences can be modelled in several ways, for example, through differences in task proficiency or in the number or range of workers' skills (Bokhorst et al. 2004a; Lian et al., 2018). In this study, we focus on differences in task proficiency, i.e. efficiency. Workers are considered to be fully flexible, i.e. they can work at all stations, but they differ in terms of their efficiency level across stations. To avoid distractions away from our focus on worker assignment rules, we chose to adopt the simplest labor and station differential efficiency matrix (Hogg et al. 1977; Malhotra \& Kher, 1994). We assume that each worker is $100 \%$ efficient at two stations to realize a balanced shop. At all other stations, worker efficiency is given by an efficiency factor $\alpha$ (see Table 2). Five different levels of this efficiency factor are considered: 60, 70, 80, 90, and 100\%. The efficiency factor is kept constant, i.e. the impact of fatigue, learning, forgetting etc. is neglected. As in Bobrowski \& Park (1993), processing times are divided by this efficiency factor to obtain the actual realized processing times. One single setting for the inter-arrival time is adopted for each setting of $\alpha$ (as described above) since the efficiency factor has a direct impact on the capacity that can be realized. 
[Take in Table 2]

\subsection{Worker Assignment Rules}

There are three major worker assignment decisions. First, when should the worker assignment decision be executed (i.e. the When Rule)? Second, for the case that there are multiple stations without a worker and therefore available to receive workers, where should a worker go (i.e. the Where Rule)? And third, for the case that more than one worker is not assigned to a station and is therefore available, who should be assigned to the station (i.e. the Who Rule)? In the case that there is more than one worker and more than one station unassigned or available at a given decision point, the Where Rule precedes the Who Rule, as in Bokhorst et al. (2004a). We do not consider a two-dimensional decision matrix given that this situation is only likely to occur if a new set of work orders enters a nearly empty shop due to the random processing times and random inter-arrival times chosen for our model. If a worker cannot be assigned to a station, then the worker goes to a central worker pool to await a new assignment.

Based on results in previous research (e.g. Thürer et al., 2019), only the centralized When Rule is considered, i.e. a worker is eligible for transfer after each work order has been completed at a station.

Meanwhile, the Who Rule is based on efficiency, i.e. the Most Efficient (MEFF) worker is chosen if more than one worker is available. As a baseline, we also include a Who Rule that neglects worker information and selects the worker Randomly (RND). To answer our first research question, we further include scenarios in which a worker can only be chosen if he/she is fully efficient at a station (the MEFFOnly rule). If no such worker exists in the set of available workers, no worker is assigned and the decision regarding who to assign to this station is postponed until another worker becomes available. Thus, additional idleness is introduced. Note that while we consider the MEFFOnly rule to be a Who Rule in our study, it is a special type of assignment rule since it does not choose from a set of workers at a given moment in time but rather delays the choice as the choice is constrained by being limited to the availability of the most efficient worker.

Finally, the Where Rule is driven by urgency, i.e. a worker is transferred to the station with the queue that contains the work order with the most urgent due date (which may be the current station or a station without a worker). To answer our second research question, two variants of this rule are considered. The first variant, the Earliest Due Date (EDD) rule, neglects critical parts while the second - the Critical Part \& Earliest Due Date \& (CPEDD) rule - considers critical parts. This means any queue that contains a critical part receives priority. A critical part 
or critical work order is hereby defined as the last item that needs to be completed to finish the assembly order. If there are ties, i.e. there are several queues containing a critical part or work order, then the one with the most urgent due date is chosen. In addition, we also evaluate a Where Rule that considers worker efficiency: the Most Efficient \& Earliest Due Date (MEFFEDD) rule. For this rule, the station at which the worker is most efficient is prioritized. Any ties are resolved by the EDD rule.

\subsection{Shop Floor Dispatching Rules}

The worker assignment decision is usually taken together with a scheduling decision, which is often reduced to a mere dispatching decision (Ostermeier, 2019). The work order that should be selected for processing next from the queue in front of a particular station is determined by a shop floor dispatching rule. In this study, three alternative dispatching rules are applied: (i)

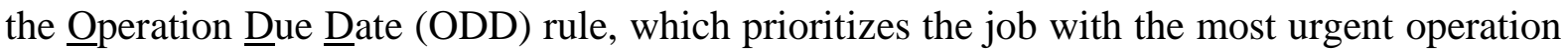
due date; (ii) the Operation Due $\underline{D} a t e ~ \&$ Critical Part (ODDCP) rule, which gives additional priority to critical parts or work orders based on the importance ratio described below; and, (iii) the Modified Operation Due Date (MODD) rule (see, e.g. Baker \& Kanet, 1983), which shifts between a focus on ODDs to complete work orders on time and a focus on speeding up work orders during periods of high load, i.e. when multiple work orders exceed their ODD (Land et al., 2015).

Calculating the operation due date $\delta_{i j}$ for the $i^{\text {th }}$ operation of a work order $j$ follows Equation (1) below. The operation due date for the last operation in the routing of a work order is equal to the due date $\delta_{j}$, while the operation due date of each preceding operation is determined by successively subtracting an allowance $c$ from the operation due date of the next operation. This allowance is based on the operation throughput times realized in preliminary simulation experiments. It differs for each setting of $\alpha$.

$\delta_{i j}=\delta_{j}-\left(n_{j}-i\right) \cdot c \quad i: 1 \ldots n_{j}$

$n_{j}-$ number of operations in the routing of work order $j$

To integrate information on the criticality of a work order for ODDCP, we use the importance ratio from Philipoom et al. (1991). This importance ratio is given as the quotient of completed work orders and total work orders that constitute an assembly order. Any ties are resolved by the ODD rule. Finally, the MODD rule prioritizes work orders according to the lowest priority number, given by the maximum of the operation due date $\delta_{i j}$ and earliest finish 
time. In other words, $\max \left(\delta_{i j}, t+p_{i j}\right)$ for an operation with processing time $p_{i j}$, where $t$ refers to the time when the dispatching decision is taken.

\subsection{Experimental Design and Performance Measures}

The experimental factors are summarized in Table 3. A full factorial design with 135 scenarios $(5 \times 1 \times 3 \times 3 \times 3)$ was used. Each scenario was replicated 100 times. Results were collected over 10,000 time units following a warm-up period of 3,000 time units. These parameters allowed us to obtain stable results whilst keeping the simulation run time to a reasonable level. Finally, the performance measures considered in this study are summarized in Table 4 .

[Take in Table $3 \&$ Table 4]

\section{Results}

To give a first indication of the performance impact of our experimental factors, statistical analysis of our results was conducted using an ANOVA (Analysis of Variance). ANOVA is here based on a block design, which is typically used to account for known sources of variation in an experiment. In our ANOVA, we treat the efficiency factor $\alpha$ as the blocking factor. This allows the main effects of this environmental factor and the main and interaction effects of our three control related factors - the Where Rule, Who Rule, and dispatching rule - to be captured. The results are presented in Table 5. All main effects, except for the dispatching rule in terms of the percentage of tardy work orders, were found to be statistically significant. Similarly, all two-way and three-way interactions were found to be statistically significant for all performance measures considered.

\section{[Take in Table 5]}

The Scheffé multiple comparison procedure was also applied to the results for the assembly orders to obtain a first indication of the direction and size of the performance differences. Table 6 gives the $95 \%$ confidence interval. If this interval includes zero, performance differences are not considered to be statistically significant. We can observe significant performance differences for all pairs for at least one performance measure. In terms of our first research question, the results suggest that it is advisable to introduce additional worker idle time in DRC shops with worker heterogeneity to ensure workers only work at their most efficient station(s), since MEFFOnly appears to outperform all other Who rules. Note that the strong effect of the MEFFOnly rule also provides an explanation for why the Who Rule was found to have the largest impact in our ANOVA results (Table 5). However, further analysis is required as this 
outcome is likely to depend on the level of $\alpha$. Meanwhile, in terms of our second research question, we observe that critical parts should be considered when assigning workers in DRC assembly job shops, since both the CPEDD and ODDCP rules have the potential to outperform alternative Where rules and dispatching rules. This will be explored further in Section 4.1 and Section 4.2 where detailed results are presented for a homogeneous and heterogeneous labor force, respectively. A discussion of the results that presents a further analysis of the 'hidden' impact of heterogeneous labor is then presented in Section 4.3.

[Take in Table 6]

\subsection{Performance Assessment - Homogeneous Labor Force}

Performance results for a homogeneous labor force, i.e. where $\alpha=100 \%$, are given in Table 7 . Since labor is homogeneous, the Who Rule and the efficiency-based Where Rule (MEFFEDD) have no performance impact and so the corresponding results are not presented. The following can be observed from the relevant results:

- Where Rule: Considering the critical part as an element of the Where Rule (CPEDD) significantly improves assembly order performance regardless of the dispatching rule applied.

- Dispatching Rule: Considering the critical part at dispatching significantly improves performance if combined with the CPEDD Where Rule. In other words, both the dispatching rule and the Where Rule should consider the critical part. If ODDCP is combined with EDD then the mean tardiness of assembly orders increases. Meanwhile, for MODD we observe a deterioration in assembly order performance since the MODD rule's shortest processing time element neglects the coordination of work orders.

[Take in Table 7]

\subsection{Performance Assessment - Heterogeneous Labor Force}

The main message from our analysis of performance under a homogeneous labor force - i.e. that considering the critical part when making the decision concerning where to move workers to is essential in DRC assembly job shops - also holds for a heterogeneous labor force. Here however, considering the efficiency as part of the Where Rule is even more important than considering the criticality of parts. This can be observed from Table 8, which gives the individual performance results when $\alpha$ is less than $100 \%$. Note that we only present the results for ODD dispatching since the performance impact is qualitatively similar across the different 
levels of the dispatching rule. Likewise, there were no performance differences across the different Where Rules if the MEFFOnly Who Rule was applied for this experimental setting. We therefore only present one result, which is equal for all.

In general, considering efficiency as part of the Where Rule appears to have a stronger performance impact than considering efficiency as part of the Who Rule. A possible explanation for this is that, in a DRC shop where labor is the primary constraint, it is much more likely that a worker has several stations from which to choose (Where Rule) than it is that there are several workers for one station to choose between (Who Rule). In other words, the Who Rule will have less of an impact than the Where Rule since it is used more infrequently. Meanwhile, additional efficiency gains can be obtained by combining the MEFFEDD Where Rule with the MEFF Who Rule. Finally, the MEFFOnly rule is the best-performing Who Rule at higher degrees of labor heterogeneity. While it is outperformed at higher levels of $\alpha$ by the RND and MEFF Who rules if these rules are combined with the MEFFEDD Where Rule, it leads to the best performance when $\alpha$ is below $70 \%$ and leads to comparable performance when $\alpha$ is at $80 \%$.

[Take in Table 8]

\subsection{Discussion}

\subsubsection{Discussion of Results}

Our study provides three major contributions to the available literature on DRC shops. It highlights that:

1. The criticality of a part or work order should be considered in an assembly job shop when making worker assignment decisions. In general, the best performance can be achieved if the dispatching and worker assignment rules are aligned. This is consistent with findings in shops with high priority jobs presented in earlier studies (e.g. Kher 2000).

2. Considering efficiency as part of the Where Rule - as was the case in Bobrowski \& Park (1993) - has a stronger performance impact than considering efficiency as part of the Who Rule, as was the case in Bokhorst et al. (2004a). The Who and Where Rules are used in different situations. It is less likely that there are several workers available for one machine in shops where labor is the main constraint. Consequently, the Who Rule is used less often and has less of an impact. Still, the Where and Who Rule can and should play complementary roles. 
3. Introducing worker idle time leads to the best-performing Who Rule, i.e. the MEFFOnly rule, in our simulations. This questions the perspective of Bokhorst et al. (2004a) who saw reducing worker idle time as a main objective. While reducing worker idle time is important, it is not beneficial if this is at the expense of realized worker efficiency. This result reemphasizes earlier literature, which argued that it is more beneficial to have some highly specialized labor (e.g. Bobrowski \& Park, 1993; Malhotra \& Kher, 1994; Felan \& Fry, 2001). It also extends these results by arguing that training workers so they are efficient at only one station may be enough, since it makes more sense to let operators wait for work than to keep them from being idle by reallocating them to another station where they are less efficient.

\subsubsection{The Hidden Effect of a Heterogeneous Labor Force}

Apart from our main results and their contribution to the literature, having a heterogeneous labor force also had an effect that we consider worthy of further discussion. In order to obtain comparable results for the different levels of $\alpha$, we had to adjust our inter-arrival time such that the utilization rate remained at $90 \%$ for the scenarios where worker efficiency is neglected by the worker assignment rule. However, this adjustment could not be based on the arithmetic mean, i.e. the sum of all elements $(6 \times 1+12 \times \alpha)$ divided by the number of elements (18). We had to recognize that the distribution of the realized processing time is the result of two independent distributions (i.e. the processing time distribution and the distribution of realized worker efficiency). To assess this impact, we created random numbers for 5,000 operations and calculated the resulting processing time for different values of alpha ranging from 10 to $100 \%$. The results are given in Figure 1. We observe that although the median remains around one time unit, there is a significant non-linear increase in the realized mean (as given in the legend), which goes far beyond the increase that would be expected from using the arithmetic mean of the efficiency matrix.

\section{[Take in Figure 1]}

Some additional experiments were executed to explore this 'hidden' impact of worker heterogeneity further. To avoid distractions away from our focus on worker assignment rules, we chose the simplest labor and station differential efficiency matrix (Hogg et al., 1977; Malhotra \& Kher, 1994). But, Malhotra \& Kher (1994) used three different matrix structures labor differential, station differential, and machine and station differential - which are schematized in Table 9. While the arithmetic mean of the efficiency of all three matrices should be equal, the realized efficiency is different for each matrix. For an $\alpha$ of $50 \%$, the arithmetic 
mean is 21 (the sum of all elements) divided by 36 (the number of elements). This mean efficiency of 0.583 is realized by the station differential matrix. Meanwhile, the labor differential matrix realizes higher efficiencies (0.631), and the labor and station differential matrix realizes lower efficiencies $(0.565)$. Note that these values are realized for the RND Who Rule and the EDD Where Rule, which both neglect worker efficiency. However, while worker efficiency is neglected by the worker assignment rules it is still reflected in the queue state, i.e. whether or not there is work in the queue. This explains the impact of the labor and station differential matrix. Meanwhile, for the labor differential matrix, the most highly efficient worker completes jobs faster and is consequently available more often than worker with the lowest efficiency.

\section{[Take in Table 9]}

The above re-emphasizes that the structure of the efficiency matrix itself also has a direct performance effect. Apart from its implications for future research (to be discussed below), there is a major message here for practice - that labor heterogeneity cannot simply be neglected. Hence, rather than basing worker assignment on some other measure, labor efficiency should always be considered when making worker assignment decisions.

\section{Conclusions}

This study was motivated by observing a practical case of an assembly job shop with dual resource constraints and heterogeneous labor. More generally, most shops are in fact constrained by more than one resource, e.g. by machines and labor. Likewise, most workers in practice differ somehow in their proficiency. Consequently, a large body of literature on DRC shops has emerged, including research on DRC shops with a heterogeneous labor force. This research typically focuses on worker assignment rules, i.e. on decisions concerning when to move workers, where workers should be moved to, and who to move. Although the decisions concerning when and where to move workers has received broad research attention, the decision concerning who to allocate to a station has received less attention. Moreover, the existing literature assumes that workers are assigned as soon as they become available, or research even seeks to minimize the risk of worker idleness. Our study has questioned this assumption.

In answer to our first research question - is it advisable to introduce additional worker idle time in DRC shops with worker heterogeneity to ensure workers only work at their most efficient station(s)? - our simulation results highlight that the gains from staying put at the most 
efficient station(s) can outweigh the losses incurred through idle time waiting for work to arrive, with a Who Rule that only allows workers to go to their most efficient station performing the best in our simulation experiments. Hence this option should be considered when selecting a worker assignment rule in practice. Moreover, the setting of the assembly job shop also raises the issue of work order coordination. The worker assignment rule determines when capacity becomes available at a station and thus impacts job progress on the shop floor. Our second research question therefore asked: Should critical parts be considered when assigning workers in DRC assembly job shops? Our simulation result highlights that considering the critical part or work order is important, leading to significant improvements under a homogeneous labor force. But if labor is heterogeneous then the focus should be on efficiency.

\subsection{Managerial Implications}

A key message from our study is that if labor is heterogeneous in its proficiency then it is important that this is recognized as it will surface in the realized average efficiency of workers even if it is not recognized. A second important managerial implication is that our results question the need for cross-training, at least when it comes to realizing high worker efficiencies. Training workers so they are highly efficient at only one station may be sufficient, since it may make more sense to allow workers to wait for work than it does to send them to another station where they are less efficient just to avoid them being idle. However, there are three important related issues to consider. First, each shop is different and has different characteristics that have to be taken into account. We have simulated a general model, but this means that the findings are likely to require contextualizing and refining for specific practical settings. Second, high worker efficiency is not necessarily beneficial to other performance outcomes, such as throughput times. Third, cross-training remains a major means of coping with unexpected events, such as machine breakdowns or worker absenteeism, since it increases worker flexibility. This must also be taken into consideration by practicing managers.

\subsection{Limitations and Future Research}

A main limitation of our study is that we have only considered one When Rule and based all of our Where Rules on urgency. Different When and Where rules could be applied in future research. Similarly, the experimental setting could be extended to incorporate different environmental factors, e.g. different structures of the efficiency matrix, different coefficients of variation for the processing times, different degrees of due date tightness, and so on. We recognize both limitations, but we also consider our experimental design to be justified by the need to keep the study focused on worker assignment rules. Specifically, research on the 
performance impact of the structure of the efficiency matrix is worthy of further attention. This structure has an impact on the realized efficiency, even if efficiency is neglected as part of the worker assignment rule. This includes the consideration of different chaining approaches or different link structures, for example, stations and workers (as in our study and most DRC research) or job operations and workers. Future research could also explore how efficiency matrices should be designed to provide guidance on effective worker cross-training. Finally, future research could consider dynamic efficiencies. While we have considered worker efficiency to be static, fatigue or proficiency losses due to labor attrition or forgetting are likely to create dynamic efficiencies in practice. This could include research that explores how ergonomic aspects should be considered to avoid proficiency losses (e.g. Hochdörffer et al., 2018).

\section{References}

Adam, N. R., Bertrand, J. W. M., \& Surkis, J., 1987. Priority assignment procedures in multilevel assembly job shops, IIE Transactions, 19, 3, 317-328.

Araz, Ö.U., \& Salum, L., 2010, A multi-criteria adaptive control scheme based on neural networks and fuzzy inference for DRC manufacturing systems, International Journal of Production Research, 48, 1, 251-270.

Baker, K.R., \& Kanet, J.J., 1983, Job shop scheduling with modified operation due-dates, Journal of Operations Management, 4, 1, 11-22.

Bobrowski, P.M., \& Park, P.S., 1993, An evaluation of labor assignment rules when workers are not perfectly interchangeable, Journal of Operations Management, 11, 257-268.

Bobrowski, P.M., \& Park, P.S., 1989, Work Release Strategies in a Dual Resource Constrained Job Shop, OMEGA, 17, 2, 177-188.

Bokhorst, J.A.C., \& Gaalman, G.J.C., 2009, Cross-training workers in Dual Resource Constrained systems with heterogeneous processing times, International Journal of Production Research, 47, 22, 6333-6356.

Bokhorst, J.C.A., Slomp, J., \& Molleman, E., 2004b, Development and evaluation of crosstraining policies for manufacturing teams, IIE Transactions, 36, 10, 969-984,

Bokhorst, J.C.A., Slomp, J., \& Gaalman G.J.C., 2004a, On the who-rule in Dual Resource Constrained (DRC) manufacturing systems, International Journal of Production Research, 42, 23, 5049-5074.

Brusco, M.J., \& Johns, T.R., 1998, Staffing a multiskilled workforce with varying level of productivity: An analysis of cross-training policies, Decision Sciences, 29, 2, 499-515. 
ElMaraghy, H., Patel., V., \& Abdallah, I.B., 2000, Scheduling of Manufacturing Systems Under Dual-Resource Constraints Using Genetic Algorithms, Journal of Manufacturing Systems, 19, 3, 186-201.

Elvers, D.A., \& Trevelen, M.D., 1985, Job-shop vs. hybrid flow-shop routing in a dual resource constrained system, Decision Sciences, 16, 2, 213-222.

Felan, J.T., \& Fry, T.D., 2001, Multi-level heterogeneous worker flexibility in a Dual Resource Constrained (DRC) job-shop, International Journal of Production Research, 39, 14, 30413059.

Felan, J.T., Fry, T.D., \& Philipoom, P.R., 1993, Labor flexibility and staffing levels in a dualresource constrained job shop, International Journal of Production Research, 31, 10, 2487 2506.

Fredendall, L.D., Melnyk, S.A., \& Ragatz, G., 1996, Information and scheduling in a dual resource constrained job shop, International Journal of Production Research, 34, 10, 2783 2802.

Fry, T.D., Kher, H.V., \& Malhotra, M.K., 1995, Managing worker flexibility and attrition in dual resource constrained job shops, International Journal of Production Research, 33, 8, 2163-2179.

Hochdörffer, J., 2018, Staff scheduling in job rotation environments considering ergonomic aspects and preservation of qualifications, Journal of Manufacturing Systems, 46, 103-114.

Hogg, G. L., Maggard, M. J. and Phillips, D. T., 1977, Parallel-channel, Dual Resource Constrained queueing systems with heterogeneous resources, AIIE Transactions, 9, 352362.

Hottenstein, M.P., \& Bowman, S.A., 1998, Cross-training and Worker flexibility: A review of DRC System research, The Journal of High Technology Management Research, 9, 2, 157 174.

Jaber, M.Y., \& Neumann, W.P., 2010, Modelling worker fatigue and recovery in dual-resource constrained systems, Computers \& Industrial Engineering, 59, 75-84.

Jensen, J.B., 2000, The impact of resource flexibility and staffing decisions on cellular and departmental shop performance, European Journal of Operational Research, 127, 279-296.

Jordan, W.C., \& Graves, S.C., 1995, Principles on the Benefits of Manufacturing Process Flexibility, Management Science, 41, 4, 577-594.

Kannan, V.R., \& Jensen, J.B., 2004, Learning and labour assignment in a dual resource constrained cellular shop, International Journal of Production Research, 42, 7, 1455-1470. 
Kher, H.V., 2000, Examination of worker assignment and dispatching rules for managing vital customer priorities in dual resource constrained job shop environments, Computers and Operations Research, 27, 525-537.

Kher, H.V., Malhotra, M.K., Philipoom, P.R., \& Fry, T.D., 1999, Modeling simultaneous worker learning and forgetting in dual resource constrained systems, European Journal of Operational Research, 115, 158-172.

Komaki, G.M., Sheikh, S., \& Malakooti, B., 2019, Flow shop scheduling problems with assembly operations: a review and new trends, International Journal of Production Research, 57, 10, 2926-2955,

Land, M.J., Stevenson, M., Thürer, M., \& Gaalman, G.J.C., 2015, Job Shop Control: In Search of the Key to Delivery Improvements, International Journal of Production Economics, 168, 257-266.

Lei, D., \& Guo, X., 2015, An effective neighbourhood search for scheduling in dual-resource constrained interval job shop with environmental objective, International Journal of Production Economics, 159, 296-303.

Lei, D., \& Guo, X., 2014, Variable neighbourhood search for dual-resource constrained flexible job shop scheduling, International Journal of Production Research, 52, 9, 2519-2529.

Li, J., Huang, Y., \& Niu, X., 2016, A branch population genetic algorithm for dual-resource constrained job shop scheduling problem, Computers \& Industrial Engineering, 102, 113131.

Lian, J., Liu, C.G., Li, W.J. \& Yin, Y., 2018, A multi-skilled worker assignment problem in seru production systems considering the worker heterogeneity, Computers \& Industrial Engineering, 118, 366-382.

Lu, H. L, Huang, G. Q. \& Yang, H. D., 2011, Integrating order review/release and dispatching rules for assembly job shop scheduling using a simulation approach, International Journal of Production Research, 49, 3, 647- 669.

Malhotra, M.K., \& Kher, H.V., 1994, An evaluation of worker assignment policies in dual resource-constrained job shops with heterogeneous resources and worker transfer delays, International Journal of Production Research, 32, 5, 1087-1103.

Malhotra, M.K., Fry, T.D., Kher, H.V., \& Donohue, J.M., 1993, The Impact of Learning and Labor Attrition on Worker Flexibility in Dual Resource Constrained Job Shops, Decision Sciences, 24, 3, 641-664.

Maxwell, W. L. \& Mehra, M., 1968, Multiple-Factor rules for sequencing with assembly constraints, Naval Research Logistics Quarterly, 15, 241-254. 
Melnyk, S.A., \& Ragatz, G.L., 1989, Order review/release: research issues and perspectives, International Journal of Production Research, 27, 7, 1081-1096.

Mourtzis, D., 2019, Simulation in the design and operation of manufacturing systems: state of the art and new trends, International Journal of Production Research, (in print).

Nelson, R.T., 1967, Labor and Machine Limited Production Systems, Management Science, $13,9,648-671$.

Ostermeier, F.F., 2019, The impact of human consideration, schedule types and product mix on scheduling objectives for unpaced mixed-model assembly lines, International Journal of Production Research, (in print).

Park., S.P., 1991, The examination of worker cross-training in a dual resource constrained job shop, European Journal of Operational Research, 51, 291-299.

Park, S.P., \& Bobrowski, P.M., 1989, Job Release and Labor Flexibility in a Dual Resource Constrained Job Shop, Journal of Operations Management, 8, 3, 230-249.

Philipoom, P., Russell, R., \& Fry, T., 1991, A preliminary investigation of multi-attribute based sequencing rules for assembly shops, International Journal of Production Research, 29, 4, 739-753.

Rochette, R. and Sadowski, R.P., 1976, A statistical comparison of the performance of simple dispatching rules for a particular set of job shops, International Journal of Production Research, 14, 63-75.

Salum, L., \& Araz, Ö.U., 2009, Using the when/Where Rules in dual resource constrained systems for a hybrid push-pull control, International Journal of Production Research, 47, 6, 1661-1677.

Sammarco, M., Fruggiero, F., Neumann, W.P., \& Lambiase, A., 2014, Agent-based modelling of movement rules in DRC systems for volume flexibility: human factors and technical performance, International Journal of Production Research, 52, 3, 633-650.

Sculli, D., 1980, Priority dispatching rules in job shops with assembly operations and random delays, Omega, 8, 2, 227-234.

Shi, F., Zhao, S.K., \& Meng, Y., 2019, Hybrid algorithm based on improved extended shifting bottleneck procedure and GA for assembly job shop scheduling problem, International Journal of Production Research, (in print).

Silva, C., Roque, L., \& Almeida, A., 2006, MAPP - A web-based decision support system for the mould industry, Decision Support Systems, 42, 2, 999-1014. 
Stevenson, M. \& Silva, C., 2008, Theoretical development of a workload control methodology: Evidence from two case studies, International Journal of Production Research, 46, 11, 3107-3131.

Stevenson, M., Huang, Y., Hendry L.C. \& Soepenberg, E., 2011, The theory \& practice of workload control: A research agenda \& implementation strategy, International Journal of Production Economics, 131, 2, 689-700.

Thürer, M., Stevenson, M., \& Renna, P., 2019, Workload Control in Dual Resource Constrained High-Variety Shops: An Assessment by Simulation, International Journal of Production Research, (in print)

Thürer, M., Stevenson, M., Silva, C., \& Huang, G.Q., 2012, The Application of Workload Control in Assembly Job Shops: An Assessment by Simulation, International Journal of Production Research, 50, 18, 5048-5062.

Treleven, M.D., 1989, A Review of the Dual Resource Constrained System Research, IIE Transactions, 21, 3, 279-287

Yue, H., Slomp, J., Molleman, E., \& Van Der Zee, D.J., 2008, Worker flexibility in a parallel dual resource constrained job shop, International Journal of Production Research, 46, 2, 451-467.

Xu, J., Xu., X., \& Xie, S.Q., 2011, Recent developments in Dual Resource Constrained (DRC) system research, European Journal of Operational Research, 215, 309-318.

Zamiska, J.R., Jaber, M.Y., and Kher, H.V., 2007, Worker deployment in dual resource constrained systems with a task-type factor, European Journal of Operational Research, $177,1507-1519$.

Zhang, J., Wang, W., \& Xu, X., 2017, A hybrid discrete particle swarm optimization for dualresource constrained job shop scheduling with resource flexibility, Journal of Intelligent Manufacturing, 28, 1961-1972.

Zheng, X.L., \& Wang, L., 2016, A knowledge-guided fruit fly optimization algorithm for dual resource constrained flexible job-shop scheduling problem, International Journal of Production Research, 54, 18, 5554-5566. 
Table 1: Summary of Simulated Shop and Job Characteristics

\begin{tabular}{|c|c|c|}
\hline 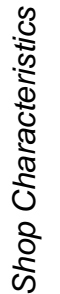 & $\begin{array}{r}\text { Shop Type } \\
\text { Routing Variability } \\
\text { No. of Stations } \\
\text { No. of Workers } \\
\text { Interchange-ability of Stations } \\
\text { Station Capacities }\end{array}$ & $\begin{array}{l}\text { Dual Resource Constrained Assembly Job Shop } \\
\text { Random routing; no-re-entrant flows } \\
6 \\
3 \\
\text { No interchange-ability } \\
\text { All equal }\end{array}$ \\
\hline 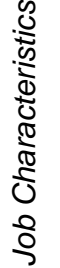 & $\begin{array}{r}\text { No. of Work Orders per Assembly Order } \\
\text { No. of Operations per Work Order } \\
\text { Operation Processing Times (100\% Eff.) } \\
\text { Due Date Determination Procedure } \\
\text { Inter-Arrival Times }\end{array}$ & $\begin{array}{l}\text { Discrete Uniform }[2,6] \\
\text { Discrete Uniform }[1,6] \\
\text { 2-Erlang; (mean =1) } \\
\text { Due Date = Entry Time+ } d ; d U \sim[65,100] \\
\text { Exp. Distribution }\end{array}$ \\
\hline
\end{tabular}

Table 2: Efficiency Matrix

\begin{tabular}{|c|c|c|c|c|c|c|}
\hline & Station 1 & Station 2 & Station 3 & Station 4 & Station 5 & Station 6 \\
\hline Worker 1 & $100 \%$ & $100 \%$ & $\alpha$ & $\alpha$ & $\alpha$ & $\alpha$ \\
\hline Worker 2 & $\alpha$ & $\alpha$ & $100 \%$ & $100 \%$ & $\alpha$ & $\alpha$ \\
\hline Worker 3 & $\alpha$ & $\alpha$ & $\alpha$ & $\alpha$ & $100 \%$ & $100 \%$ \\
\hline
\end{tabular}

Table 3: Experimental Design

\begin{tabular}{|c|c|}
\hline Factor & Levels \\
\hline $\begin{array}{r}\text { Efficiency Factor } \alpha \\
\text { (5 levels) }\end{array}$ & $60,70,80,90,100 \%$ (homogenous labor) \\
\hline $\begin{array}{r}\text { When Rule } \\
\text { (1 level) }\end{array}$ & Centralized, i.e. after each job completion \\
\hline $\begin{array}{r}\text { Where Rule } \\
\text { (3 levels) }\end{array}$ & $\begin{array}{l}\text { Earliest Due Date (EDD); Critical Part \& Earliest Due Date (CPEDD); Most } \\
\text { Efficient \& Earliest Due Date (MEFFEDD) }\end{array}$ \\
\hline $\begin{array}{r}\text { Who Rule } \\
\text { (3 levels) }\end{array}$ & Random (RND); Most Efficient (MEFF); Most Efficient Only (MEFFOnly) \\
\hline $\begin{array}{r}\text { Dispatching Rule } \\
\text { (3 levels) }\end{array}$ & $\begin{array}{l}\text { Operation Due Date (ODD); Operation Due Date \& Critical Part (ODDCP); } \\
\text { Modified Operation Due Date (MODD) }\end{array}$ \\
\hline
\end{tabular}


Table 4: Summary of Performance Measures

\begin{tabular}{|l|c|l|}
\hline \multicolumn{1}{|c|}{ Name } & Abbreviation & Brief Description \\
\hline $\begin{array}{l}\text { Assembly Order } \\
\text { Lead Time }\end{array}$ & AOtlead & $\begin{array}{l}\text { The assembly order completion date (i.e. all work orders } \\
\text { belonging to an assembly order are completed) minus the } \\
\text { time at which the assembly order entered the system. }\end{array}$ \\
\hline $\begin{array}{l}\text { Percentage Tardy } \\
\text { Assembly Order }\end{array}$ & AOP $_{\text {tardy }}$ & The percentage of assembly orders which are tardy. \\
\hline $\begin{array}{l}\text { Assembly Order } \\
\text { Mean Tardiness }\end{array}$ & AOMtardy & $\begin{array}{l}\text { That is } T_{l}=\max \left(0, L_{l}\right), \text { with } L_{l} \text { being the lateness of assembly } \\
\text { order I (i.e. the actual delivery date minus the due date). }\end{array}$ \\
\hline $\begin{array}{l}\text { Work Order Lead } \\
\text { Time }\end{array}$ & WOtlead & $\begin{array}{l}\text { The work order completion date minus the time at which the } \\
\text { work order entered the system. }\end{array}$ \\
\hline $\begin{array}{l}\text { Percentage Tardy } \\
\text { Work Order }\end{array}$ & WOPtardy & The percentage of work orders which are tardy. \\
\hline Worker Efficiency & Eff. & The average of the realized worker efficiency across stations. \\
\hline
\end{tabular}


Table 5: ANOVA Results

\begin{tabular}{|c|c|c|c|c|c|c|}
\hline & Source of Variance & $\begin{array}{l}\text { Sum of } \\
\text { Squares }\end{array}$ & $\begin{array}{l}\text { Degrees } \\
\text { of freedom }\end{array}$ & $\begin{array}{r}\text { Mean } \\
\text { Squares }\end{array}$ & F-Ratio & $\mathrm{p}$-Value \\
\hline \multirow{9}{*}{ AOtlead } & Alpha $(\alpha)$ & 297165.66 & 4 & 74291.42 & 195.73 & 0.00 \\
\hline & Where & 27130.99 & 2 & 13565.49 & 35.74 & 0.00 \\
\hline & Who & 723853.45 & 2 & 361926.72 & 953.56 & 0.00 \\
\hline & Dispatching (Disp) & 23627.95 & 2 & 11813.97 & 31.13 & 0.00 \\
\hline & Where $x$ Who & 10216.05 & 4 & 2554.01 & 6.73 & 0.00 \\
\hline & Where $x$ Disp & 178484.26 & 4 & 44621.06 & 117.56 & 0.00 \\
\hline & Who $\times$ Disp & 75964.88 & 4 & 18991.22 & 50.04 & 0.00 \\
\hline & Where $x$ Who $x$ Disp & 89927.82 & 8 & 11240.98 & 29.62 & 0.00 \\
\hline & Error & 5112200.40 & 13469 & 379.55 & & \\
\hline \multirow{9}{*}{$\mathrm{AOP}_{\text {tardy }}$} & Alpha $(\alpha)$ & 11.14 & 4 & 2.78 & 175.96 & 0.00 \\
\hline & Where & 1.34 & 2 & 0.67 & 42.33 & 0.00 \\
\hline & Who & 33.55 & 2 & 16.78 & 1060.22 & 0.00 \\
\hline & Dispatching (Disp) & 0.25 & 2 & 0.13 & 7.93 & 0.00 \\
\hline & Where $\times$ Who & 0.46 & 4 & 0.11 & 7.20 & 0.00 \\
\hline & Where x Disp & 8.29 & 4 & 2.07 & 130.93 & 0.00 \\
\hline & Who $\times$ Disp & 2.20 & 4 & 0.55 & 34.77 & 0.00 \\
\hline & Where $x$ Who $x$ Disp & 4.58 & 8 & 0.57 & 36.16 & 0.00 \\
\hline & Error & 213.14 & 13469 & 0.02 & & \\
\hline \multirow{9}{*}{ AOMtardy } & Alpha $(\alpha)$ & 59715.05 & 4 & 14928.76 & 103.66 & 0.00 \\
\hline & Where & 2736.16 & 2 & 1368.08 & 9.50 & 0.00 \\
\hline & Who & 87260.53 & 2 & 43630.27 & 302.96 & 0.00 \\
\hline & Dispatching (Disp) & 1243.69 & 2 & 621.85 & 4.32 & 0.01 \\
\hline & Where $x$ Who & 2184.47 & 4 & 546.12 & 3.79 & 0.00 \\
\hline & Where x Disp & 26107.20 & 4 & 6526.80 & 45.32 & 0.00 \\
\hline & Who x Disp & 3971.03 & 4 & 992.76 & 6.89 & 0.00 \\
\hline & Where $x$ Who $x$ Disp & 17650.68 & 8 & 2206.33 & 15.32 & 0.00 \\
\hline & Error & 1939721.90 & 13469 & 144.01 & & \\
\hline \multirow{9}{*}{ WOtlead } & Alpha $(\alpha)$ & 159788.14 & 4 & 39947.04 & 166.59 & 0.00 \\
\hline & Where & 19480.05 & 2 & 9740.02 & 40.62 & 0.00 \\
\hline & Who & 562609.47 & 2 & 281304.73 & 1173.15 & 0.00 \\
\hline & Dispatching (Disp) & 11486.71 & 2 & 5743.36 & 23.95 & 0.00 \\
\hline & Where $x$ Who & 6783.80 & 4 & 1695.95 & 7.07 & 0.00 \\
\hline & Where $x$ Disp & 118809.25 & 4 & 29702.31 & 123.87 & 0.00 \\
\hline & Who $\times$ Disp & 55561.03 & 4 & 13890.26 & 57.93 & 0.00 \\
\hline & Where $x$ Who $x$ Disp & 60616.76 & 8 & 7577.09 & 31.60 & 0.00 \\
\hline & Error & 3229672.40 & 13469 & 239.79 & & \\
\hline \multirow{9}{*}{ WOP $_{\text {tardy }}$} & Alpha $(\alpha)$ & 4.70 & 4 & 1.17 & 144.65 & 0.00 \\
\hline & Where & 0.66 & 2 & 0.33 & 40.40 & 0.00 \\
\hline & Who & 17.39 & 2 & 8.69 & 1070.26 & 0.00 \\
\hline & Dispatching (Disp) & 0.01 & 2 & 0.01 & 0.72 & 0.48 \\
\hline & Where $\times$ Who & 0.24 & 4 & 0.06 & 7.27 & 0.00 \\
\hline & Where x Disp & 4.02 & 4 & 1.01 & 123.82 & 0.00 \\
\hline & Who $\times$ Disp & 1.01 & 4 & 0.25 & 30.94 & 0.00 \\
\hline & Where $x$ Who $x$ Disp & 2.39 & 8 & 0.30 & 36.74 & 0.00 \\
\hline & Error & 109.40 & 13469 & 0.01 & & \\
\hline
\end{tabular}


Table 6: Results for Scheffé Multiple Comparison Procedure: Assembly Order Results

\begin{tabular}{|c|c|c|c|c|c|c|c|c|}
\hline & \multirow{2}{*}{ Rule (x) } & \multirow{2}{*}{ Rule (y) } & \multicolumn{2}{|c|}{ AOtlead } & \multicolumn{2}{|c|}{$\mathrm{AOP}_{\text {tardy }}$} & \multicolumn{2}{|c|}{$\mathrm{AOM}_{\text {tardy }}$} \\
\hline & & & lower ${ }^{11}$ & upper & lower & upper & lower & upper \\
\hline \multirow{3}{*}{$\begin{array}{l}\text { Where } \\
\text { Rule }\end{array}$} & CPEDD & EDD & -3.681 & -1.670 & -0.023 & -0.010 & -1.535 & -0.296 \\
\hline & MEFFEDD & EDD & -4.260 & -2.249 & -0.030 & -0.017 & -1.610 & -0.371 \\
\hline & MEFFEDD & CPEDD & $-1.585^{\star}$ & 0.426 & -0.014 & -0.001 & $-0.694^{*}$ & 0.545 \\
\hline \multirow{3}{*}{$\begin{array}{l}\text { Who } \\
\text { Rule }\end{array}$} & MEFF & RND & 1.980 & 3.991 & 0.012 & 0.025 & 1.053 & 2.292 \\
\hline & MEFFOnly & RND & -14.829 & -12.818 & -0.102 & -0.089 & -4.978 & -3.740 \\
\hline & MEFFOnly & MEFF & -17.815 & -15.804 & -0.120 & -0.107 & -6.651 & -5.412 \\
\hline \multirow{3}{*}{$\begin{array}{l}\text { Dispatching } \\
\text { Rule }\end{array}$} & ODDCP & ODD & -2.060 & -0.049 & $-0.001^{*}$ & 0.012 & $-1.220^{*}$ & 0.019 \\
\hline & MODD & ODD & 1.121 & 3.132 & 0.004 & 0.017 & $-0.540^{*}$ & 0.698 \\
\hline & MODD & ODDCP & 2.175 & 4.186 & $-0.001^{*}$ & 0.012 & 0.060 & 1.299 \\
\hline
\end{tabular}

Table 7: Results for Homogeneous Labor

\begin{tabular}{|l|l|c|c|c|c|c|}
\hline $\begin{array}{l}\text { Where } \\
\text { Rule }\end{array}$ & $\begin{array}{l}\text { Dispatching } \\
\text { Rule }\end{array}$ & AOt lead & AOP tardy & AOM $_{\text {tardy }}$ & WOt lead & WOP tardy \\
\hline EDD & ODD & 49.1 & $16.8 \%$ & 6.3 & 40.6 & $10.6 \%$ \\
\hline CPEDD & ODD & 45.2 & $13.1 \%$ & 3.9 & 39.0 & $10.0 \%$ \\
\hline EDD & ODDCP & 45.4 & $14.9 \%$ & 5.3 & 35.8 & $8.8 \%$ \\
\hline CPEDD & ODDCP & 42.6 & $11.9 \%$ & 3.6 & 35.5 & $7.7 \%$ \\
\hline EDD & MODD & 51.7 & $17.1 \%$ & 8.7 & 40.8 & $10.0 \%$ \\
\hline CPEDD & MODD & 46.5 & $12.1 \%$ & 4.8 & 38.6 & $8.3 \%$ \\
\hline
\end{tabular}


Table 8: Results for Heterogeneous Labor and ODD Dispatching

\begin{tabular}{|c|c|c|c|c|c|c|c|c|}
\hline$\alpha$ & $\begin{array}{l}\text { Where } \\
\text { Rule }\end{array}$ & $\begin{array}{l}\text { Who } \\
\text { Rule }\end{array}$ & AOtlead & $\mathrm{AOP}_{\text {tardy }}$ & $\mathrm{AOM}_{\text {tardy }}$ & WOtlead & $\mathrm{WOP}_{\text {tardy }}$ & Eff. \\
\hline \multirow{7}{*}{$90 \%$} & EDD & RND & 49.2 & $16.7 \%$ & 5.8 & 40.4 & $10.6 \%$ & $93.3 \%$ \\
\hline & CPEDD & RND & 49.1 & $16.2 \%$ & 5.5 & 42.6 & $11.5 \%$ & $93.3 \%$ \\
\hline & MEFFEDD & RND & 35.2 & $4.7 \%$ & 1.0 & 29.3 & $2.8 \%$ & $97.1 \%$ \\
\hline & EDD & MEFF & 50.8 & $17.8 \%$ & 7.1 & 42.1 & $11.7 \%$ & $93.6 \%$ \\
\hline & CPEDD & MEFF & 47.4 & $14.9 \%$ & 5.0 & 41.0 & $11.3 \%$ & $93.6 \%$ \\
\hline & MEFFEDD & MEFF & 34.8 & $4.8 \%$ & 0.9 & 28.9 & $3.0 \%$ & $97.5 \%$ \\
\hline & All equal & MEFFOnly & 41.5 & $7.2 \%$ & 1.7 & 33.8 & $4.6 \%$ & $100.0 \%$ \\
\hline \multirow{7}{*}{$80 \%$} & EDD & RND & 56.7 & $22.1 \%$ & 9.5 & 47.0 & $14.7 \%$ & $86.5 \%$ \\
\hline & CPEDD & RND & 52.3 & $18.3 \%$ & 6.6 & 45.2 & $14.5 \%$ & $86.5 \%$ \\
\hline & MEFFEDD & RND & 29.8 & $1.4 \%$ & 0.2 & 24.2 & $0.8 \%$ & $93.3 \%$ \\
\hline & EDD & MEFF & 52.2 & $19.0 \%$ & 7.3 & 43.1 & $13.5 \%$ & $87.1 \%$ \\
\hline & CPEDD & MEFF & 50.2 & $16.7 \%$ & 5.6 & 43.2 & $12.5 \%$ & $87.1 \%$ \\
\hline & MEFFEDD & MEFF & 30.0 & $1.8 \%$ & 0.3 & 24.4 & $0.9 \%$ & $94.3 \%$ \\
\hline & All equal & MEFFOnly & 31.1 & $2.0 \%$ & 0.3 & 24.6 & $1.0 \%$ & $100.0 \%$ \\
\hline \multirow{7}{*}{$70 \%$} & EDD & RND & 58.5 & $23.1 \%$ & 9.7 & 48.4 & $15.8 \%$ & $79.6 \%$ \\
\hline & CPEDD & RND & 57.6 & $23.2 \%$ & 8.9 & 49.9 & $16.9 \%$ & $79.6 \%$ \\
\hline & MEFFEDD & RND & 27.9 & $0.6 \%$ & 0.0 & 22.2 & $0.2 \%$ & $88.9 \%$ \\
\hline & EDD & MEFF & 58.4 & $24.1 \%$ & 9.8 & 48.3 & $16.3 \%$ & $80.6 \%$ \\
\hline & CPEDD & MEFF & 56.4 & $22.4 \%$ & 8.6 & 48.9 & $17.4 \%$ & $80.5 \%$ \\
\hline & MEFFEDD & MEFF & 26.6 & $0.5 \%$ & 0.0 & 21.1 & $0.3 \%$ & $90.3 \%$ \\
\hline & All equal & MEFFOnly & 24.9 & $0.5 \%$ & 0.0 & 19.1 & $0.2 \%$ & $100.0 \%$ \\
\hline \multirow{7}{*}{$60 \%$} & EDD & RND & 73.1 & $34.2 \%$ & 18.2 & 61.0 & $25.8 \%$ & $72.6 \%$ \\
\hline & CPEDD & RND & 67.3 & $30.9 \%$ & 13.4 & 58.5 & $23.5 \%$ & $72.6 \%$ \\
\hline & MEFFEDD & RND & 26.8 & $0.2 \%$ & 0.0 & 20.7 & $0.1 \%$ & $83.6 \%$ \\
\hline & EDD & MEFF & 70.7 & $32.7 \%$ & 17.2 & 58.9 & $23.5 \%$ & $73.8 \%$ \\
\hline & CPEDD & MEFF & 64.1 & $27.6 \%$ & 13.2 & 55.8 & $21.7 \%$ & $73.9 \%$ \\
\hline & MEFFEDD & MEFF & 25.8 & $0.2 \%$ & 0.0 & 20.1 & $0.1 \%$ & $85.9 \%$ \\
\hline & All equal & MEFFOnly & 20.7 & $0.1 \%$ & 0.0 & 15.5 & $0.0 \%$ & $100.0 \%$ \\
\hline
\end{tabular}


Table 9: Different Efficiency Matrix Structures (based on Malhotra \& Kher (1994))

\begin{tabular}{|c|c|c|c|c|c|c|c|}
\hline & & Station 1 & Station 2 & Station 3 & Station 4 & Station 5 & Station 6 \\
\hline \multirow{6}{*}{$\begin{array}{r}\text { Labor } \\
\text { differential }\end{array}$} & Worker 1 & $100 \%$ & $100 \%$ & $100 \%$ & $100 \%$ & $100 \%$ & $100 \%$ \\
\hline & Worker 2 & $\alpha$ & $\alpha$ & $\alpha$ & $\alpha$ & $\alpha$ & $\alpha$ \\
\hline & Worker 3 & $\alpha$ & $\alpha$ & $\alpha$ & $\alpha$ & $\alpha$ & $\alpha$ \\
\hline & Worker 4 & $\alpha$ & $\alpha$ & $\alpha$ & $\alpha$ & $\alpha$ & $\alpha$ \\
\hline & Worker 5 & $\alpha$ & $\alpha$ & $\alpha$ & $\alpha$ & $\alpha$ & $\alpha$ \\
\hline & Worker 6 & $\alpha$ & $\alpha$ & $\alpha$ & $\alpha$ & $\alpha$ & $\alpha$ \\
\hline \multirow{6}{*}{$\begin{array}{r}\text { Station } \\
\text { differential }\end{array}$} & Worker 1 & $100 \%$ & $\alpha$ & $\alpha$ & $\alpha$ & $\alpha$ & $\alpha$ \\
\hline & Worker 2 & $100 \%$ & $\alpha$ & $\alpha$ & $\alpha$ & $\alpha$ & $\alpha$ \\
\hline & Worker 3 & $100 \%$ & $\alpha$ & $\alpha$ & $\alpha$ & $\alpha$ & $\alpha$ \\
\hline & Worker 4 & $100 \%$ & $\alpha$ & $\alpha$ & $\alpha$ & $\alpha$ & $\alpha$ \\
\hline & Worker 5 & $100 \%$ & $\alpha$ & $\alpha$ & $\alpha$ & $\alpha$ & $\alpha$ \\
\hline & Worker 6 & $100 \%$ & $\alpha$ & $\alpha$ & $\alpha$ & $\alpha$ & $\alpha$ \\
\hline \multirow{6}{*}{$\begin{array}{l}\text { Labor and } \\
\text { Station } \\
\text { differential }\end{array}$} & Worker 1 & $100 \%$ & $\alpha$ & $\alpha$ & $\alpha$ & $\alpha$ & $\alpha$ \\
\hline & Worker 2 & $\alpha$ & $100 \%$ & $\alpha$ & $\alpha$ & $\alpha$ & $\alpha$ \\
\hline & Worker 3 & $\alpha$ & $\alpha$ & $100 \%$ & $\alpha$ & $\alpha$ & $\alpha$ \\
\hline & Worker 4 & $\alpha$ & $\alpha$ & $\alpha$ & $100 \%$ & $\alpha$ & $\alpha$ \\
\hline & Worker 5 & $\alpha$ & $\alpha$ & $\alpha$ & $\alpha$ & $100 \%$ & $\alpha$ \\
\hline & Worker 6 & $\alpha$ & $\alpha$ & $\alpha$ & $\alpha$ & $\alpha$ & $100 \%$ \\
\hline
\end{tabular}




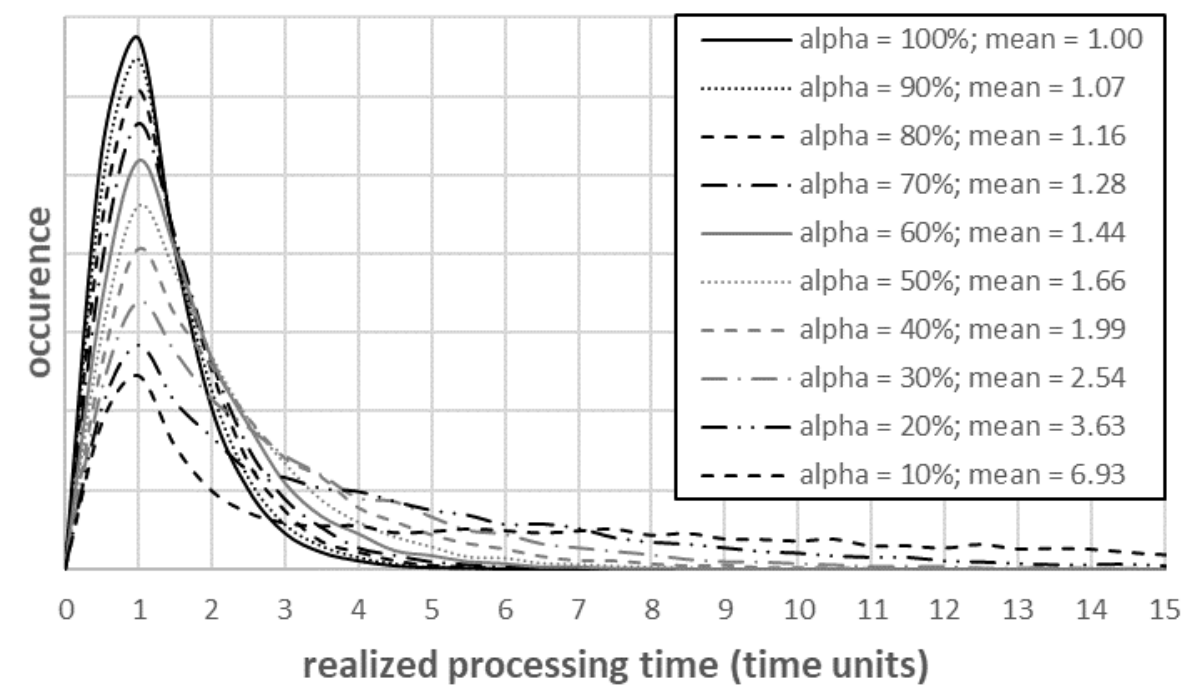

Figure 1: Distribution of Realized Processing Times for Different Levels of the Efficiency Factor $\alpha$ 